\title{
Calidad y Disponibilidad de los Recursos Hídricos en tres Microcuencuas Costeras del Municipio de Tola, Nicaragua
}

Valeria Delgado, Heyddy Calderón, Yelba Flores, Thelma Salvatierra.

Centro para la Investigación en Recursos Acuáticos de Nicaragua, Universidad Nacional Autónoma de Nicaragua, Apdo. Postal 4598, Managua, Nicaragua. Correo electrónico: valeria.delgado@cira-unan.edu.ni

Recepcionado: 13 Noviembre 2009 / Aceptado: 02 Junio 2010

\section{Resumen}

L as actividades económicas, el crecimiento de la población en general; así como los cambios climáticos globales, han aumentado la presión sobre los recursos hídricos en el país. Esto se refleja tanto en una disminución en la disponibilidad, así como en la pérdida de calidad de estos recursos. En consecuencia, los gobiernos municipales han formado alianzas estratégicas con organismos internacionales e instituciones académicas para producir información base necesaria para la creación y ejecución de planes de ordenamiento territorial, a fin de planificar futuras demandas de agua. El desarrollo turístico en la franja costera del Municipio de Tola ha generado cambios en el uso del suelo, desprotección de las zonas de recarga de los acuíferos, posible riesgo de intrusión marina por el bombeo excesivo en la zona costera, y ha creado problemas con la disposición de residuos sólidos. Los resultados indican que hay disponibilidad de agua, tanto superficial como subterránea en las tres microcuencas costeras estudiadas; sin embargo su calidad se ha afectado por la presencia de heces fecales en las aguas de los pozos y por residuos de carbamatos en los ríos. El Índice Biótico de Familias de Hilsenhoff arrojó que el agua es relativamente mala en la parte alta y media de las 3 microcuencas. Fue identificada una especie nueva para el Pacífico Sur de Nicaragua (Theodoxus sp.) y una reportada por primera vez en 1972 en San Juan del Sur (Trinectes fonsecensis). Aunque el agua está disponible en cantidad, su calidad restringe su uso para consumo humano; por lo que es necesario concientizar a la población del municipio en cuanto a la protección, limpieza y uso adecuado de los recursos hídricos.

Palabras Clave: calidad del agua, disponibilidad, microcuenca, Índice Hilsenhoff, Nicaragua 


\section{Abstract}

Economic activities, population growth, as well as global climate change, have increased pressure on water resources in Nicaragua. This is reflected in a decrease in the availability and the loss of quality of these resources. Consequently, local governments have formed strategic alliances with international organizations and academic institutions to produce basic information necessary for the creation and implementation of land use plans, in order to prepare for future water demands. Tourism development in the coastal strip of the municipality of Tola has produced changes in land use, lack of protection of recharge areas of aquifers, the potential risk of seawater intrusion by over-pumping of groundwater in the coastal zone, and problems with solid waste disposal. The results of this study indicate water availability in both, surface and groundwater, in the three coastal watersheds studied, although its quality has been affected by the presence of fecal material in water wells, and carbamate pesticide residues in rivers. The Family Biotic Index by Hilsenhoff showed that the water is relatively poor in the upper and middle sections of the 3 watersheds. A new species for Nicaragua's South Pacific (Theodoxus sp.) was identified, and one first reported in 1972 in San Juan del Sur (Trinectes fonsecensis). Although water is available in quantity, problems of quality restrict its use for human consumption; so it is necessary to raise public awareness of the municipality in terms of protection, cleanliness and proper use of water resources.

\section{Introducción}

El Municipio de Tola es el mayor de los 10 municipios pertenecientes al departamento de Rivas, y está localizado entre las coordenadas $11^{\circ} 26^{\prime}$ latitud Norte y $85^{\circ} 56^{\prime}$ longitud oeste en la costa Pacífico. Su territorio tiene una extensión de $474 \mathrm{~km}^{2}$ y una población de 23161 habitantes. La temperatura media anual en el Municipio oscila entre los 25 y $27^{\circ} \mathrm{C}$, con una precipitación anual promedio de 1,500 y 1,600mm (INIFOM, 1997). Tola está dividida en 11 microcuencas, compartidas en su parte alta por los municipios de Belén y Rivas; siendo las de mayor área Brito, Escalante y Nagualapa (figura 1).

La economía de los habitantes se basa en la producción de musáceas (guineos y plátanos) y de granos básicos (arroz, frijol, maíz y sorgo). Algunas salineras se desarrollan en sus costas. Igualmente, la población se dedica a la crianza de ganado a pequeña escala. Las actividades de cultivo y ganadería se realizan principalmente en las zonas altas y medias del municipio.

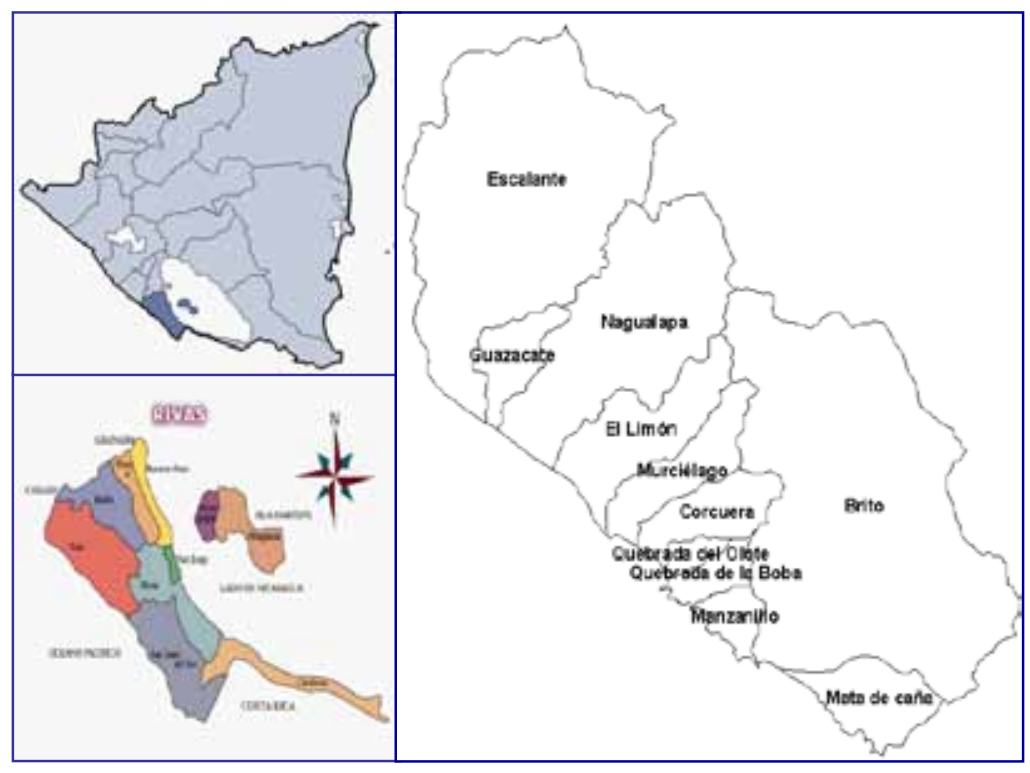

Figura 1. Localización. 
El servicio de agua potable y alcantarillado está disponible únicamente en el casco urbano de Tola, Nancimí, Las Salinas de Nagualapa y La Virgen Morena; el resto de la población se abastece de agua a través de pozos excavados. En algunos sectores, los ríos son bombeados para irrigación de cultivos y breva de ganado, actividades que han modificado el uso de suelo y generado la desprotección de las zonas de recarga de los acuíferos.

En los últimos años se han construido numerosos "resorts" turísticos (balnearios y surfing) en las costas del municipio, en donde se han perforado pozos para satisfacer la excesiva demanda de agua en estos complejos hoteleros, campos de golf y restaurantes; sobre todo en las épocas de mayor afluencia estacional de turistas. Esto ha conllevado a que se desconozca el volumen de extracción en la zona costera (posible riesgo de contaminación del recurso por intrusión de aguas salinas debido al bombeo excesivo), a la alteración de los ecosistemas litorales, contaminación de los mares y playas por deposición de desechos sólidos, entre otros.

Otras actividades como el ecoturismo desarrollado en la zona montañosa y la construcción de la carretera costanera en el municipio, multiplicarán el flujo de inversionistas y turistas al municipio, generando mayor presión sobre los recursos hídricos.

Es así que las microcuencas de Brito, Nagualapa y Escalante han sido identificadas por su extensión (más del 50\% del área del municipio), como primordiales para la futura planificación de la disponibilidad (calidad y cantidad) de agua, la cual es de vital importancia para la municipalidad ante la creciente demanda que se tiene de este recurso.

\section{Materiales y Métodos}

La etapa inicial consistió en la recopilación de la información existente acerca del Municipio, con énfasis en las tres microcuencas seleccionadas. Se contó con la colaboración de la Alcaldía municipal, instituciones gubernamentales y académicas, así como también de organismos no gubernamentales (ONG's). Una vez que ésta fue procesada y analizada, se procedió a la fase de campo la cual se dividió en tres sub-etapas:

1) Caracterización Geológica e Hidrogeológica: en la que se realizaron los reconocimientos geológico e hidrogeológico (exploración geológica,inventario de fuentes de agua, medición de niveles de agua en los pozos, pruebas de infiltración, inventario de fuentes de contaminación).

2) Caracterización Hidrológica: reconocimiento hidrológico, inventario de ríos, medición de caudales, datos climáticos, características de suelo (tipo y uso).

3) Evaluación de la Calidad de los recursos hidricos superficial y subterráneo: contempla el diseño y selección de los sitios de muestreo (de acuerdo al inventario de fuentes de agua), colecta de muestras de agua superficial y subterránea; procesamiento e interpretación de los resultados de laboratorio. La evaluación de la calidad de las aguas superficiales y subterráneas se basó en su composición físico-química y bacteriológica. En adición, la calidad del agua superficial fue evaluada en cuanto a la presencia de residuos de plaguicidas organoclorados, organofosforados y carbamatos; así como también en cuanto a la cuantificación de los organismos bentónicos colectados en muestras de sedimentos de los sitios seleccionados en los ríos, cuya presencia o ausencia de especies específicas puede estar relacionada a la entrada de nutrientes y materia 
orgánica, así como también de sustancias toxicas que se descargan a los ríos.

Los análisis físico-químicos se realizaron siguiendo los procedimientos del American Public Health Association (American Public Health Association (APHA), 2005). El amonio se analizó de acuerdo a la metodología descrita por Rodier (Rodier, 1981). Mientras que la evaluación bacteriológica (coliformes totales, coliformes termotolerantes, Escherichia coli y estreptococos fecales) se realizó con la metodología del American Public Health Association (American Public Health Association (APHA), 1999). Los plaguicidas organoclorados y organofosforados fueron analizados por el método descrito en el Manual de Procedimientos Operativos Normalizados del Laboratorio de Contaminantes Orgánicos (CIRA/UNAN, 2005). La metodología para los análisis de carbamatos se encuentra descrita en Carbamate Analysis System (Method Manual Number 30804, 1989).

Los métodos para el análisis cualitativo y cuantitativo del macrozoobentos se basan en lo descrito en la American Public Health Association (American Public Health Association (APHA), 2005). También se utilizan los Procedimientos Operativos Normalizados para la determinación de la composición cualitativa y cuantitativa (CIRA/ UNAN, 2005) del macrozoobentos.

\section{Resultados y Discusión}

\section{Hidrogeología e Hidrología}

La dirección preferencial de flujo de agua subterránea es NE-SO, con descarga regional hacia el Océano Pacífico. Se distinguen cuatro acuíferos de importancia en la zona de estudio (figura 2); todos ellos tienen descarga directa al mar. Los límites de los acuíferos están entre la Formación Brito (que representa el basamento impermeable) y los aluviales del cuaternario, desarrollándose en las planicies aluviales de la parte baja de los ríos del mismo nombre.

Localmente se observa descarga hacia los principales ríos del área. Se observa una divisoria subterránea

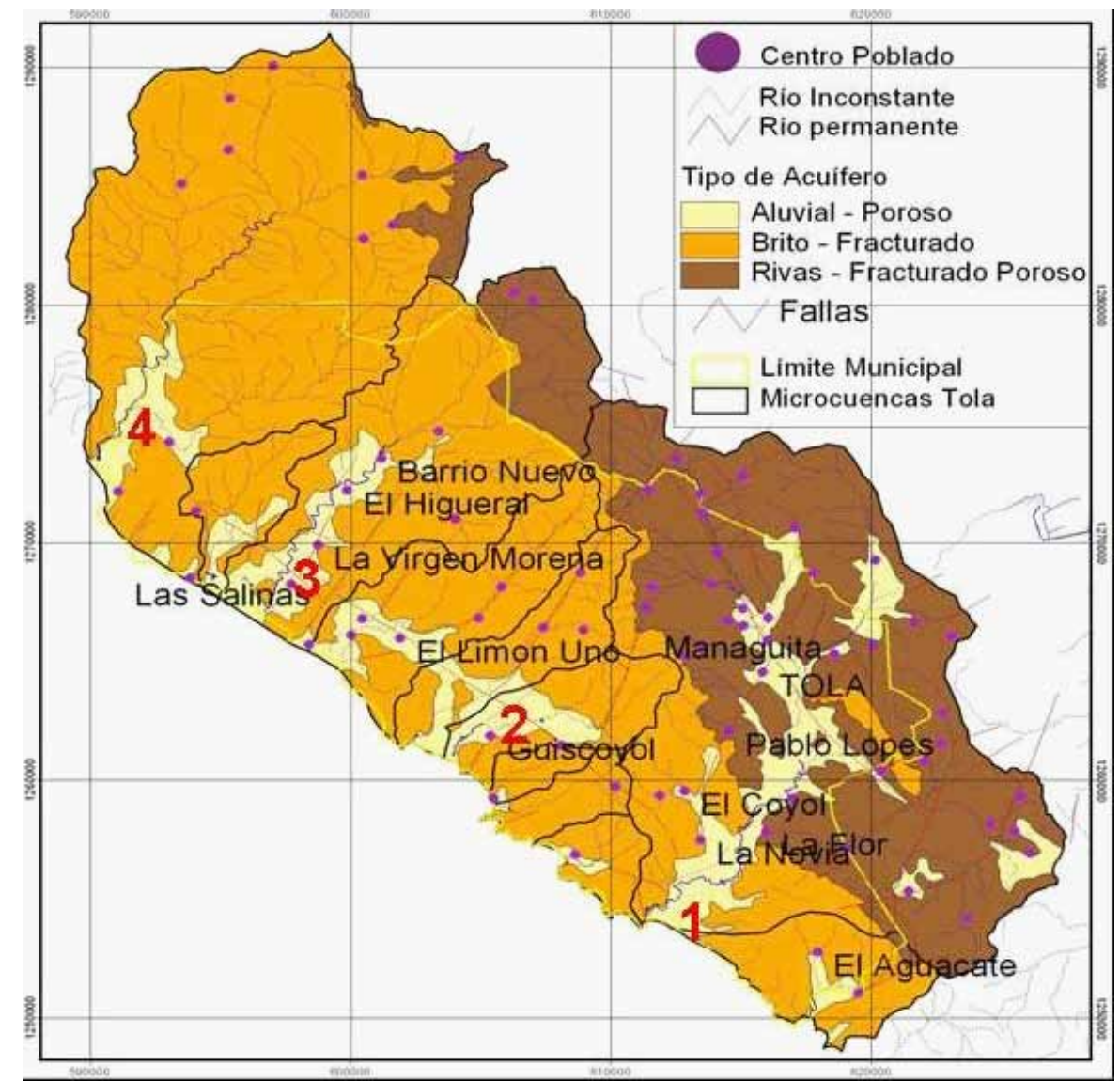

Figura 2. Acuíferos en el Municipio de Tola 


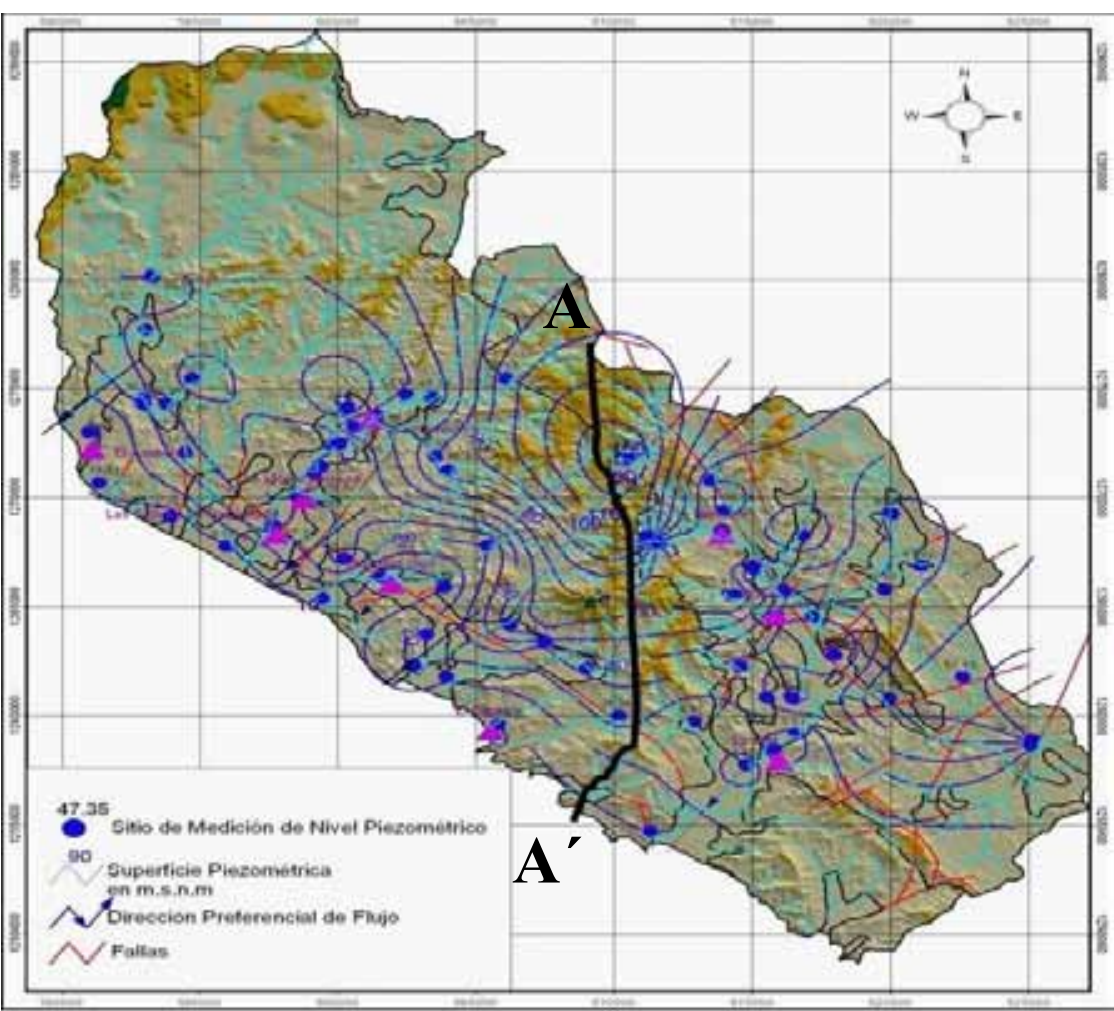

Figura 3. Piezometría en el Municipio de Tola.

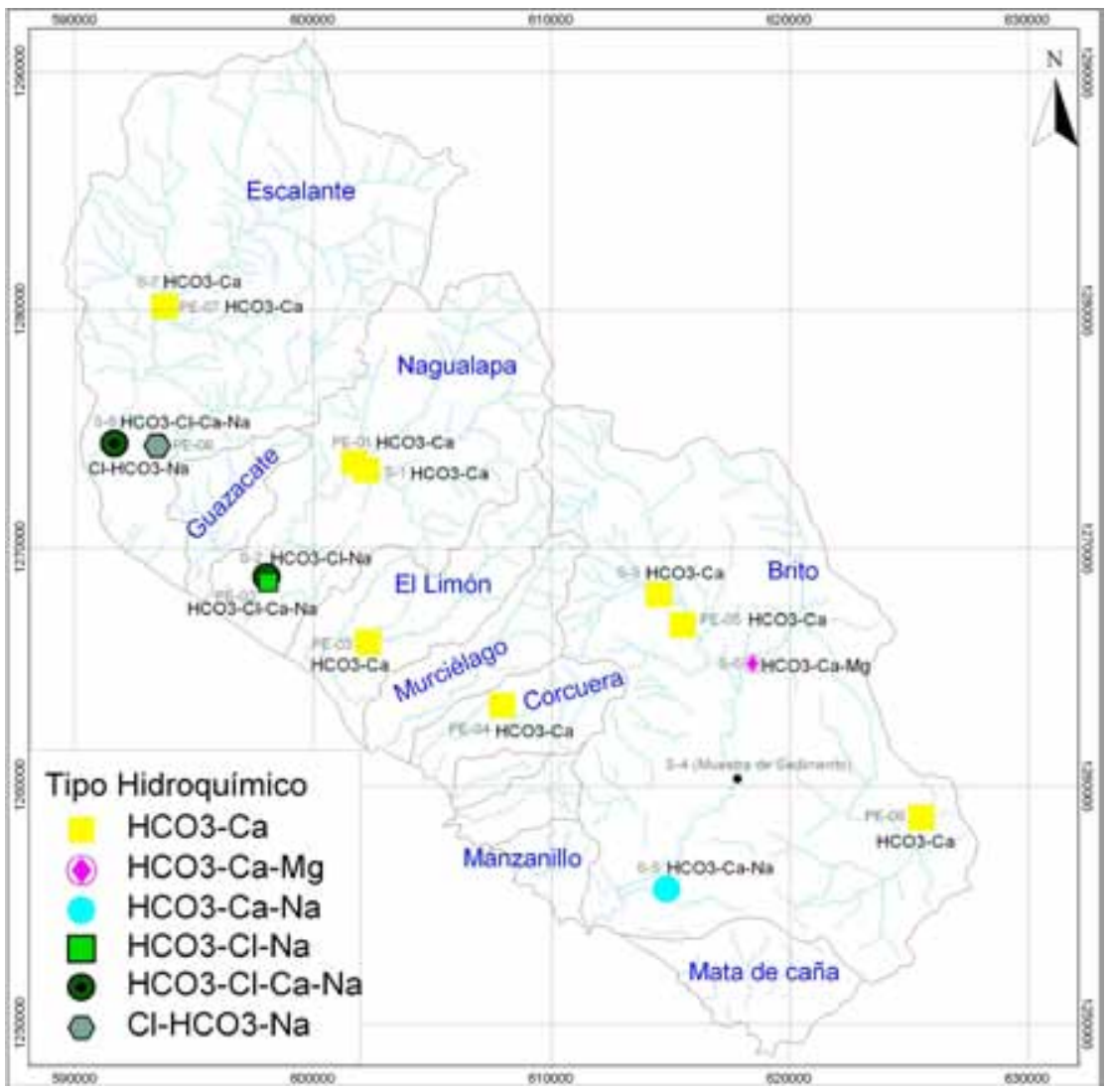

Figura 4. Tipo Hidroquímico.
(A-A'; figura 3) en el Cerro Escoba y La Mohosa, donde el flujo se divide hacia el río Brito y los acuíferos de menor extensión localizados entre Murciélago y Limón, indicando este accidente geográfico como una zona importante para la recarga regional del acuífero. El acuífero más productivo es el localizado entre Río Murciélago y Limón, debido a que presenta mayor extensión y una zona de recarga más amplia.

Las reservas de agua subterránea son suficientes para el abastecimiento de aguadeconsumo humano; sinembargo las limitantes son la localización de los pozos, la profundidad de estos y el uso del suelo en la región. En cuanto a las aguas superficiales, es recomendable un máximo de utilización del 50\%, de manera que su aprovechamiento no vaya en detrimento de la disponibilidad. Los caudales estimados a partir de las mediciones de campo indican aporte de agua subterránea hacia los ríos durante la época de estiaje.

\section{Calidad del agua}

En base a su composición iónica, las aguas superficiales y subterráneas se clasifican predominantemente del tipo bicarbonatado-cálcico (figura 4); presentando variaciones de sodio y magnesio en la parte media de las microcuencas. En la parte baja de las microcuencas de Nagualapa y Escalante, la composición iónica es característica de las zonas de descarga 
(predominancia de iones cloruro y sodio) y mezcla de agua dulce (ríos) con agua salada.

El predominio del ión bicarbonato en las aguas subterráneas se debe a: 1) el tipo de roca (sedimentaria) predominante en la zona Pacífica; en donde las calizas, areniscas calcáreas, tobas y dacitas riolíticas, cuarzo, y anfibolitas están presentes; 2) el rango de valores de $\mathrm{pH}$ del agua subterránea, en equilibrio con el sistema de carbonatos; 3 ) el relativo poco tiempo de tránsito, de ahí que se les considere aguas de recarga.

Las aguas superficiales y subterráneas se clasifican como muy duras (Durfor y Becker, 1962), por lo que son de calidad media. El agua captada en un pozo excavado en la parte alta de Escalante es suave y por ende de buena calidad (Ambientum, 2002). Para clasificar las aguas para su uso agrícola, se utilizaron las Normas Riverside (US Salinity Laboratory Staff, 1954) a través de una relación entre la conductividad eléctrica y el índice S.A.R (relación absorción sodio). En base a esto, tanto las aguas superficiales como las subterráneas son de buena calidad aptas para el riego (C2-S1: agua con salinidad media y bajo contenido de sodio); con excepción de la parte baja de Nagualapa que es utilizable para riego pero con precauciones debido a su alta salinidad (C3-S1); esto, probablemente se deba a la actividad salinera que se realiza en esta zona.

La calidad del agua subterránea se ve mermada por la presencia de nitratos y amonio, debido a las actividades realizadas en algunos sectores del municipio (aplicación de fertilizantes nitrogenados, estiércol de corrales, vertidos de aguas residuales domésticas e industriales, lixiviados de basureros clandestinos). Las salineras presentes en Salinas de Nagualapa, incrementa el contenido de cloruros y sulfatos en el agua subterránea en esa zona. La presencia de bacterias coliformes termotolerantes, Escherichia coli y estreptococos fecales en las aguas subterráneas, evidencia una situación sanitaria, en las que existen condiciones precarias para la salud de la población. Por todo lo anteriormente expuesto,

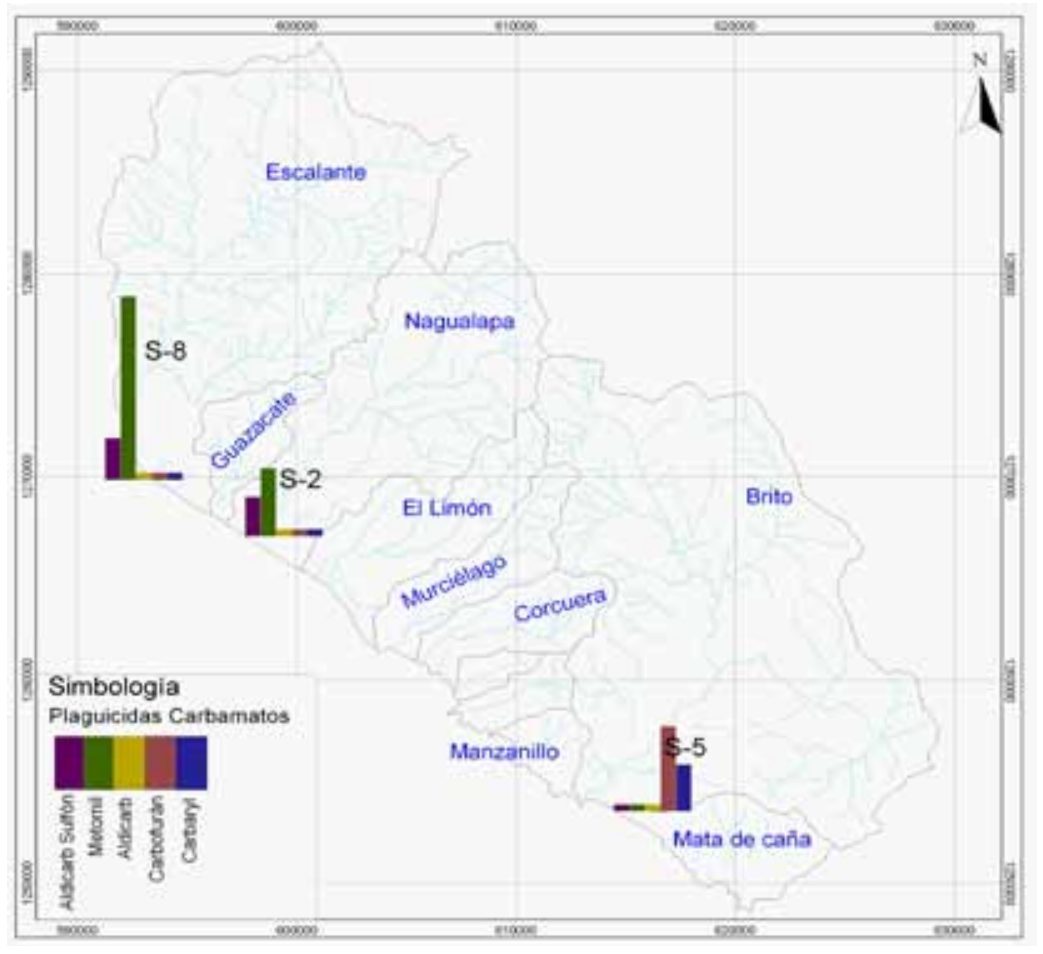

Figura 5. Carbamatos. 


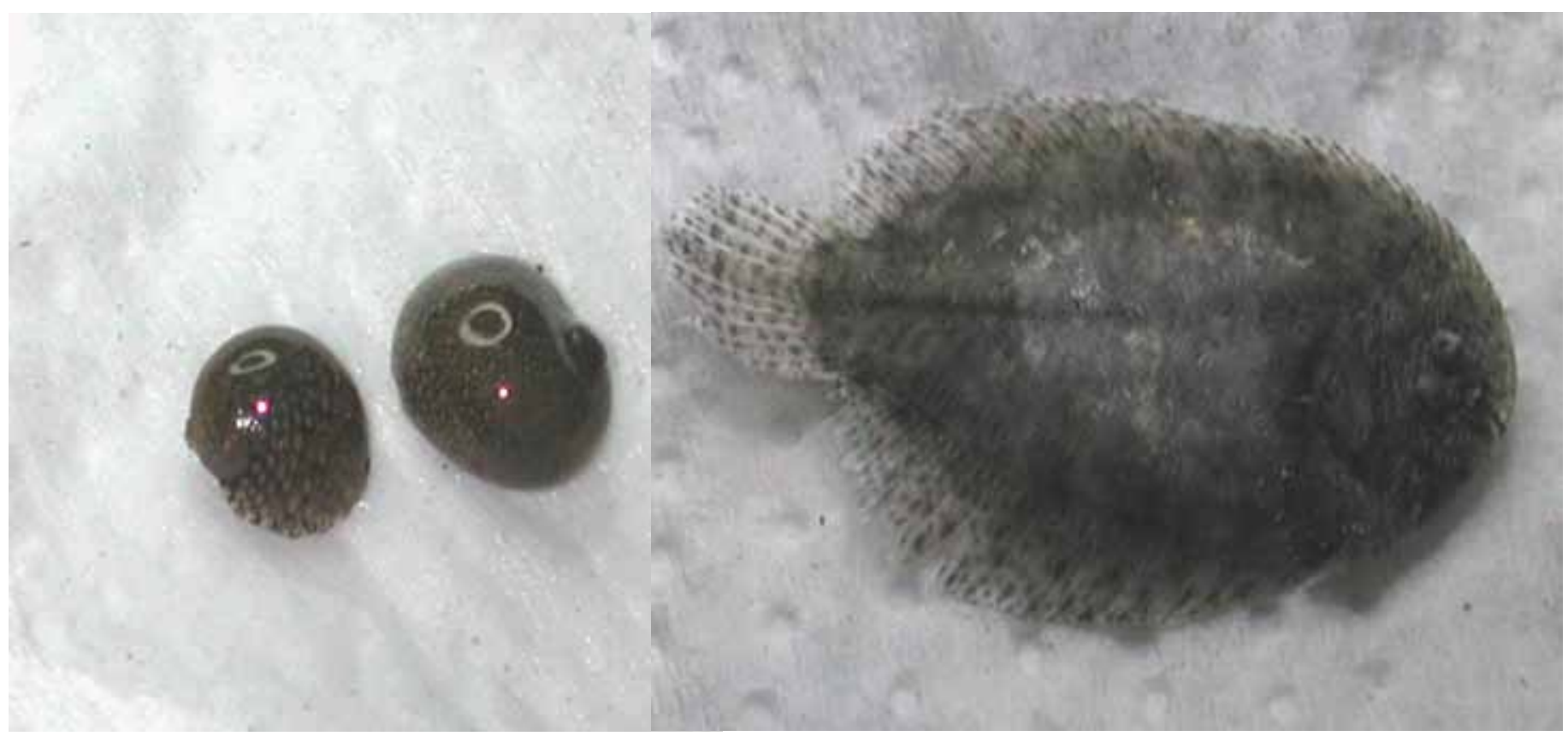

Figura 6. Theodoxus sp. y Trinectes fonsecensis (lenguado redondo).

las aguas superficiales y subterráneas no son recomendables para consumo humano (CAPRE, 1994).

El uso de los cauces de los ríos tanto para lavado como para descarga de aguas negras y grises, así como caminos y abrevaderos de ganado, ha mermado la calidad y estética de estos cuerpos de agua (valores de turbidez >5.0 UNT; valores muy pequeños o nulos de oxígeno disuelto, necesario para la degradación de sustancias orgánicas; conductividad eléctrica, sólidos totales disueltos y presencia de amonio por arriba de los valores recomendados por las normas para agua potable). El contenido de hierro en concentraciones mayores a los $0.3 \mathrm{mg} \cdot \mathrm{l}^{-1}$ recomendados por las normas (Canadian Council of Ministers of Environment (CCME), 2003, CAPRE, 1994), en ciertos puntos en los ríos, se debe al contacto del agua con el material geológico rico en hierro, presente en las Formaciones Brito y Rivas.
La falta de hábitos higiénicos en la población, así como el aporte de heces de ganado y de animales domésticos se ve reflejado con la presencia de coliformes termotolerantes, estreptococos fecales y Escherichia coli (cuya abundancia indica un serio problema sanitario); haciendo que las aguas de los ríos no se consideren aceptables para uso doméstico ni para consumo humano (CAPRE, 1994).

En la desembocadura de los ríos al mar, se analizaron residuos de plaguicidas carbamatos; detectándose aldicarb-sulfón, metomil, carbaryl y carbofurán (figura 5). La norma CAPRE (CAPRE, 1994), no reporta valor estándar para ninguno de estos compuestos. Sin embargo, las concentraciones detectadas de carbaryl y carbofurán en estos sitios, no superan los valores reportados para consumo humano para estos compuestos en las normas canadienses (Canadian Council of Ministers of Environment (CCME), 2003). Los residuos de plaguicidas organoclorados y organofosforados se 
analizaron únicamente para la desembocadura del Río Brito, sin ser detectados.

Se complementó la información química de la calidad las aguas superficiales con los resultados de los indicadores biológicos (macroinvertebrados bénticos), colectados en los sedimentos de los cauces de los ríos. Se encontró que la calidad del agua varía por sectores (Índice biótico de familias propuesto por Hilsenhoff en el año (Hilsenhoff, 1987), lo cual está asociado con la entrada de nutrientes y material orgánico.

Fueron identificadas dos especies endémicas en el área estudiada (figura 6). El Theodoxus sp. fue encontrado en el Río Salinas de Nagualapa (S-2); y el Trinectes fonsecensis se encontró en la confluencia del Río Tola y del Río Grande (S-4). Aún hay que confirmar estos hallazgos científicos realizados por el CIRA/UNAN.

$\mathrm{El}$ informe de resultados fue presentado al personal de la Alcaldía de Tola, como una herramienta concreta para el futuro manejo sostenible de los recursos hídricos en el municipio.

A pesar de contar con suficiente cantidad de recursos hídricos superficiales y subterráneos, de los cuales se debe hacer un uso consciente y adecuado, éstos se ven disminuidos por la calidad que ambos recursos presentan. El impacto de la actividad salinera en la parte baja de la microcuenca de Nagualapa es evidente. El mal uso de los cauces de los ríos ha mermado su calidad química, estética y microbiológica. Mientras que la calidad de las aguas subterráneas se ve afectada por actividades agrícolas, ganaderas y domésticas. Es notoria la falta de hábitos higiénicos en la población del municipio, ya que la abundancia de indicadores microbiológicos es muy alta, haciendo que dichas aguas no sean recomendables para consumo. Los organismos bentónicos indican variación de la calidad del agua en los sectores del municipio, debido a la entrada de nutrientes y material orgánico. Es necesario establecer campañas de limpieza y protección de los ríos, así como también de las fuentes puntuales de contaminación alrededor de los pozos.

\section{Conclusiones}

Se tiene un volumen de almacenamiento de $270 \mathrm{MMC}$ para los valles aluviales de Brito, Corcuera, entre Limón y Murciélago, Nagualapa y Escalante, considerado suficiente para la población. Hay una zona importante de recarga en las Serranías de Brito, Cerro Limón y Lomas Las Anchuras. Se calculan 1557.5 MMC de agua subterránea disponible y 352 MMC de agua superficial para las 3 microcuencas. Las aguas de los ríos están siendo impactadas por actividades antropogénicas y agrícolas. Presencia de heces fecales en las aguas de los pozos; y de residuos de plaguicidas carbamatos en las aguas de los ríos. La actividad salinera en Nagualapa impacta las aguas superficiales y subterráneas, por lo que, a diferencia de los demás sitios, éstas no se consideran aptas para riego. Fue identificada una especie nueva para Nicaragua (Theodoxus sp.) y una reportada en 1972 (Trinectes fonsencensis). 


\section{Bibliografía}

Ambientum. (2002). http://www.ambientum.com/ revistal2001 43/2001 43 AGUAS/DRZZGUAS2. $\underline{\mathrm{btm}}$

$\underline{\text { Recuperado el } 2008}$

American Public Health Association (APHA). (2005). Standard Methods for the Examination of Water and Wastewater. Washington: 21th Edition.

Canadian Council of Ministers of Environment (CCME), 2003. Canadian Quality Guidelines. Summary Table. Retrieved 2008

CAPRE, 1994. Normas Regionales para Centroamérica, Panamá y República Dominicana. Normas de Calidad para Consumo Humano. 1a Edición.

CIRA/UNAN, 2005. Manual de Procedimientos Operativos Normalizados del Laboratorio de Contaminantes Orgánicos. In CIRA/UNAN, PON-CO-01. Managua: Documento Interno CIRA/UNAN.

CIRA/UNAN, 2005. Manual de Procedimientos Operativos Normalizados del Laboratorio de Hidrobiología. In CIRA/UNAN, $M P O N-H B-03$ Tomo II - (PON-HB-08). Managua: Documento Interno CIRA/UNAN.
CIRA/UNAN, 2005. Manual de Procedimientos Operativos Normalizados del Laboratorio de Hidrobiología. In CIRA/UNAN, MPON-HB-O3 Tomo II (PON-HB-09). Managua: Documento Interno CIRA/UNAN.

Durfor, C. N., \& Becker, E., 1962. Public Water supplies of the 100 largest cities in the United States. U.S. Geological Survey Water-Supply Paper 1812 .

Hilsenhoff, W. L., 1987. An improved biotic index of organic stream pollution. The great lakes entomologist. J.N. Benthol. Vol. 20. No. 1.

INIFOM, 1997. http://www.inifom.gob.nil municipios/documentos/RIVAS/tola.pdf. Recuperado el 2008

MILLIPORE Corporation, 1989. Carbamate Analysis System Method Manual. Manual Number 30804. Fourth Edition, September. MILLIPORE Corporation Waters Chromatography Division. Publications PB.

Rodier,J.,1981.Análisis de las aguas.Aguas naturales, aguas residuales, Aguas de mar. Ed. OMEGA. 1059 Pag.

US Salinity Laboratory Staff, 1954. Diagnosis and improvement of saline and alkali sols. Handbook 60. U.S. Gov. Print Office, Washington DC. 